standards. In contrast, in the informal economy there are diverse and atypical places of work (for example street vendors in public places, industrial outworkers in their own homes or in small informal factories), status in employment (self-employed versus wage workers). These and other differences present profound challenges to the formal profession and practice of OHS. A five year, seven country study sought to understand the growing gap between what OHS conventionally provides, and what informal workers need or find useful for the improvement of their working conditions and well-being.

Methods WIEGO and its affiliates in Brazil, Ghana, India, Peru, South Africa, Tanzania, and Thailand focused on two occupational sectors in each country, selected from street vendors, headload porters, domestic workers, waste pickers, and home-based workers. Country situation analyses of the informal economy, and the provision of OHS, were followed by extensive engagement in participatory research with informal workers. Bridging platforms were used where specific OHS issues could be discussed by informal workers and authorities together.

Discussion We worked in collaboration with contacts inside and outside of government departments, member-based organisations, NGOs, trade unions and others. In-country researchers and organisations explored inter alia the reform of local market regulations to control the weights carried by men porters, the installation of first aid stands in built markets, improved access for women head porters to a national health insurance scheme, child care provision, skill upgrading for better incomes, and the development of improved work equipment. The paper concludes with a consideration of what role an influential organisation such as $\mathrm{ICOH}$ could play in promoting an OHS that could include categories of informal employment.

\section{COMMUNITY BASED FINANCING MODEL: A PILOT STUDY TO PROMOTE TOTAL WORKER HEALTH AMONGST DRIVERS IN LAGOS STATE}

CJ Okala*, B Ironsi, C Nwankwo. Occupation Health and Hygiene Service Limited

\subsection{6/oemed-2018-ICOHabstracts. 1411}

Introduction The paper will discuss a community financing based wellness model, piloted amongst drivers in Lagos State. The model builds on the hub and spoke investment model and utilises 'susu' a traditional micro-finance mechanism as an entry point. The model integrates protection from workrelated safety and health hazards with promotion of injury and illness prevention efforts to advance worker well-being.

Based on a needs assessment, the primary initiative was to establish a wellness intervention targeting a cross section of drivers involved in organised and unorganised micro and small enterprises in Lagos State.

Methods A cross-sectional survey was conducted on the first cohort (45) of 3 based on a convenience sample. A selfadministered, close-ended questionnaire recorded the participant's personal characteristics, health status, and health interests. Blood pressure and blood sugar levels were taken by trained volunteers. A repeat evaluation after the 6 month deployment of the program is planned. Key informant interviews and a satisfaction survey is planned.
Results Preliminary baseline results amongst others indicate that a significant percentage of the drivers smoked cigarettes (22\%) while $2 \%$ admitted to the use of marijuana, were overweight (84\%), and/or were not aware they had high blood pressure (10\%). Also, 42\% of surveyed drivers experienced headaches more than 3 times in a week. Other findings $* \%$ had defective and 32\% had low back which has lasted for more than 3 times in a week.

Conclusion Wellness measures targeting identified occupational health risks, emotional, spiritual and environmental aspects of health were developed. The paper will share the model, best practices, lessons learned and programme future plans.

This model can be replicated by other organised and unorganised micro and small enterprises to promote productivity and manage disease within the workforce while still promoting wellness.

\section{PERCEPTIONS OF OCCUPATIONAL HEALTH AND SAFETY IN SMALL AND MEDIUM SCALE ENTERPRISES IN LAGOS STATE, AND THE NIGERIAN OHS LAWS}

SAMUEL Oluranti. Lagos State University, Ojo, Lagos Nigeria

10.1136/oemed-2018-ICOHabstracts. 1412

Introduction The paper examines the perceptions of workers in SMSEs in Lagos, Nigeria to OHS and the Nigerian OHS laws. Issues of responsibility of stakeholders, training needs, role of trade associations, collaborating efforts on OHS, level of accessibility, conformity and adherence to the Nigerian OHS laws were examined.

Methods The study adopts both qualitative and quantitative methods of data collection from three purposively selected sawmills, mechanic villages and blacksmith cottages in three Local Government Areas of Lagos State, Nigeria, between December 2014 and June 2015. The quantitative data analyses use simple percentile, while the qualitative was content-analysed, based on the objectives of the study.

Results OHS is not a way of exploiting workers (62.7\%); government functionaries were never around on OHS issues (83.9\%); lack of awareness of OHS (81.8\%); trade associations do not emphasise on OHS (63.3\%), and no sanctions on non-compliance on OHS issues (77.2\%). Furthermore, OHS is seen as a personal issue $(77.7 \%)$, and for all stakeholders (93.9\%) and that workers need training on OHS (97.2\%). In addition, installation and maintenance of equipments in SMSEs are not guided by OHS laws (96.7\%), ministry official never visited workplaces $(87.8 \%)$, as well as Factories inspectors (93.4\%), no copies of OHS laws (97.7\%), workers not guided by OHS laws (95\%), no conformity with OHS laws (93.9\%), and OHS issues not taken seriously (69.5\%).

Conclusion The study suggests that though personal precaution is paramount for workers, collective responsibility of all stakeholders on OHS in SMSEs is imperative. Trade association in the SMSEs should also collaborate with various government agencies that have oversight functions on OHS to educate workers, and workers who flout OHS laws should be sanctioned within the confine of the laid down rules and regulations in the workplace. These will definitely improve workers' perception of OHS in the selected SMSEs. 